ISAHP 2001, Berne, Switzerland, August 2-4, 2001

\title{
USING AHP TO PRIORITIZE PROCESS CHANGE REQUESTS IN SOFTWARE PROCESS IMPROVEMENT ${ }^{1}$
}

\author{
Ipininder S. Monga \\ Wipro Infotech \\ ipininder@hotmail.com \\ Shivraj Kanungo \\ Department of Management Science, The George Washington University \\ kanungo@gwu.edu
}

Keywords: AHP, group, aggregation, process, ranking

Summary: We present a AHP based technique to grade and aggregate the processes and the projects in an organization. In particular, we present the application of group AHP to the problem of choosing process change requests (PCRs) in a software process improvement (SPI) program at IBM Global Services ${ }^{2}$. In such situations, it is crucial to ensure that all PCRs are taken and evaluated in a transparent and contextually relevant manner. In order to include diverse opinions and constituencies, the group-based approach is most appropriate. However, there are numerous variants that can be applied to such situations for group decision-making. In order to implement the option chosen by IBM we developed a Java-based system. An analysis of the process and the system is presented with implications for future development and refinement.

\section{Introduction}

This paper reports on the development of a system and its implementation to help an organization to prioritize process change requests that emanate from users. The principal objective for us was to develop a group-AHP based technique that enabled the organization to do relative grading of their projects and processes. The secondary objective was to develop a system that would unobtrusively allow participant inputs and use them to provide a ranking for the process changes. The organizational setting was IBM Global Services, Bangalore in India and the context was the process change requests that emanated as a result of the Capability Maturity Model (CMM) initiative ${ }^{3}$. The overview of process change management (PCM) process is shown in Figure 3. It can be seen that this a critical driver of this process is the frequency and quality of the process change requests that emanate from practitioners. However, if practitioners find that their process change requests (however trivial or fundamental) are not being addressed in time, then their enthusiasm to generate such requests and be proactive in process improvements wanes. Therefore, we needed to design a process and use a technique that would enable a transparent prioritization of PCRs by multiple individuals acting on behalf of practitioners, quality assurance professionals and management.

\section{Background}

We have used the underlying idea used in aggregating individual judgments (AIJ) for this paper. Forman and Peniwati (1998) suggest that when individuals are willing to, or must relinquish their own preferences (values, objectives) for the good of the organization, they act in concert and pool their judgments in such a

\footnotetext{
${ }^{1}$ This work was conducted and completed at the Department of Management Studies, Indian Institute of Technology, Delhi

${ }^{2}$ We are grateful to Dr. A. Goyal and the entire SQA group at IBM Global Services for their contribution to and participation in this project.

${ }^{3}$ IBM Global Services, India is one of the 30 organizations worldwide to have been assessed at CMM level 5.
} 


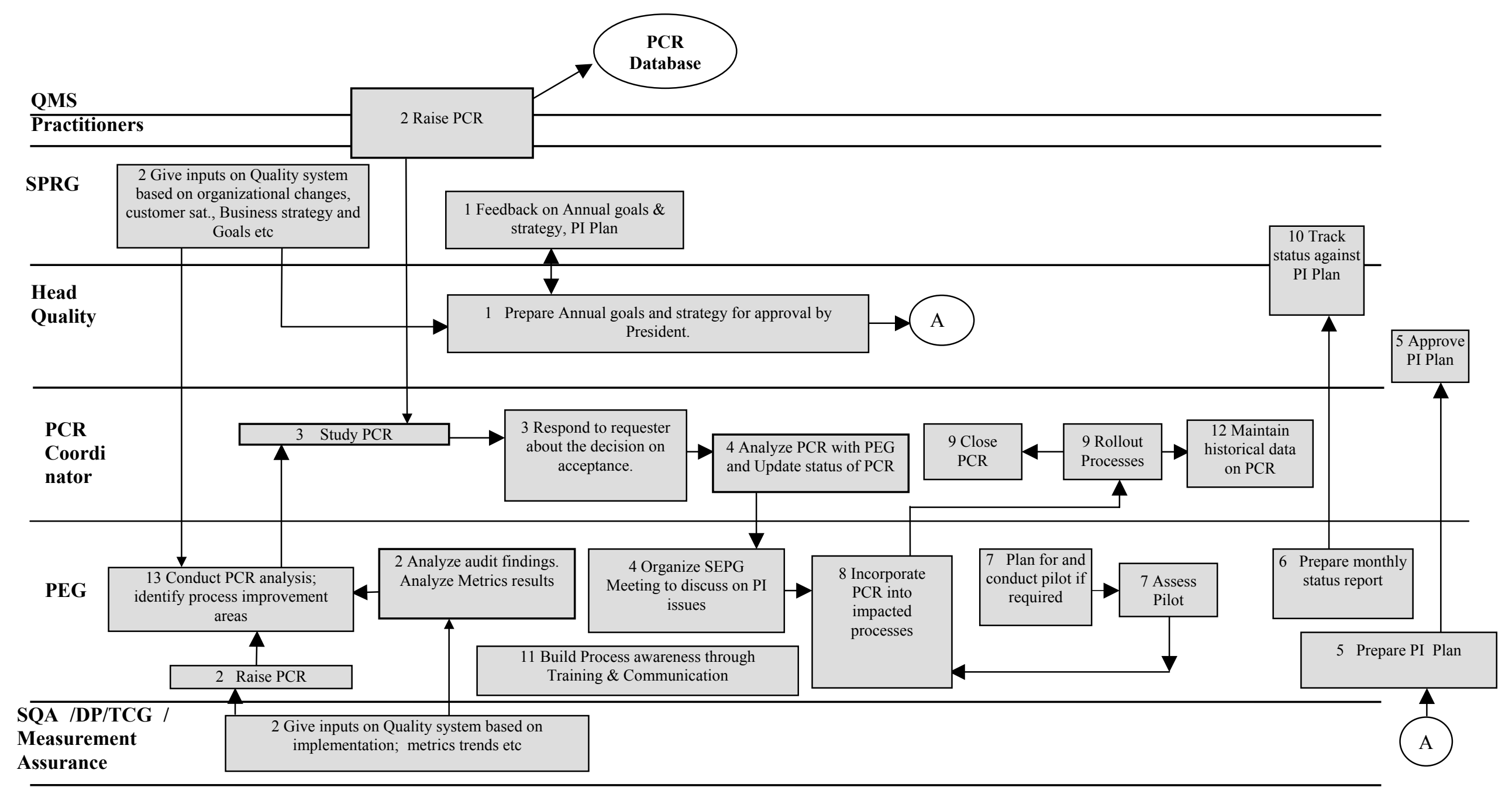

Figure 3. Overview of the PCM process 
way that the group becomes a new 'individual' and behaves like one. Our problem was to generate a set of ranks for processes that are acceptable to everyone in the group because each

member of the group is a stakeholder in seeing that they are responsible for either suggesting process improvements or acting upon them. If the group acts ins consonance, then, the Pareto principal, which Ramanathan and Ganesh (1994) claim is violated, does not remain relevant. Furthermore, since the group becomes a new 'individual' and behaves like one, the reciprocity requirement for the judgments must be satisfied and the geometric mean rather than arithmetic mean must be used.

Forman and Peniwati (1998) further suggest that when individuals are each acting on his or her own right, with different value systems, we are concerned about each individual's resulting priorities. An aggregation of each individual's resulting priorities (aggregating individual priorities - AIP) can be computed using either a geometric or arithmetic mean. Neither method will violate the Pareto principle.

Aczel and Saaty (1983) have shown that when aggregating the judgments of $n$ individuals where the reciprocal property is assumed even for a single n-tuple, only the geometric mean satisfies the Pareto principle and the homogeneity condition. Thus for all AIJ, the geometric mean must be used. As for AIP, either an arithmetic or geometric mean can be used to aggregate the individuals' priorities.

Our survey of the literature revealed that an AHP based method to rank the processes / projects is suggested by Frei and Harker (1999). However, the technique suggests by them suffers from following gaps:

a. Firstly, it does not take into account the relative importance of the criteria. That is the authors give equal weight to all the competitions for which the alternatives are evaluated. But in practical scenarios, it happens that some criteria are more significant for decision making under consideration.

b. Secondly, the technique suggested by them does not suggest the algorithms or procedures to incorporate group decision-making where the various group members give their own judgements. The algorithm suggested by them is applicable only in the situations where one individual is being involved in decision-making or single concrete scores have been obtained from a group.

c. Thirdly, there must be way to incorporate the experience, ability and qualifications of the various group members involved. This means that the judgement of the person who is more experienced or more qualified for the kind of decision under consideration should be given more weightages.

\section{Our approach}

Our approach addresses the first two of these issues. A group AHP (GAHP) system was conceptualized, designed and developed (Monga, 2000). GAHP facilitates interaction among the participants, allows the facilitator to set up topic for decision making, allows participants to express their rankings, enables the facilitator to choose from various algorithms to aggregate scores. It also explicitly supports techniques for relative grading of projects.

\section{Step 1}

The first step in developing this technique would be to do identify the criteria essential for grading the type of projects in question. We suggest that the participants should have through discussion for selecting the criteria considered essential for the success of the project.

\section{Step 2}

After selection of the criteria the participants should do an AHP to prioritize the criteria. We suggest that all the participants do individual prioritization using AHP technique.

\section{Step 3}

The next step will be that all the participants will rank or prioritize each other using AHP. This step is essential because we would like the priorities of the most experienced or most capable member of the group member to receive maximum weight. The merit in this step is that all the members of the group are generally not equal in experience, qualification and merit to grade particular type of processes or projects. 
So the experts or the participants will rate each other on the basis of the experience, qualification and any other factor or trait considered by the group to be essential for appropriate project grading.

\section{Step 4}

Once the group has obtained individual priorities for both the criteria and the experts the next challenge is to synthesize the scores of all the participants to arrive at the ranking for the group. For this step we suggest that the aggregation of individual priorities method (geometric mean method or arithmetic mean method) should be used for obtaining the group scores for the ranking of experts. Let us say that $\left[\mathrm{e}_{1}, \mathrm{e}_{2}, \mathrm{e}_{3}, \ldots . ., \mathrm{e}_{\mathrm{n}}\right]$ be the eigenvector obtained by synthesizing the priorities of various experts.

\section{Step 5}

The next step is to multiply the eigenvector obtained for an individual participant by its priority obtained in step 5. E.g. If $\left[\mathrm{c}_{11}, \mathrm{c}_{12}, \mathrm{c}_{13}, \ldots ., \mathrm{c}_{1 \mathrm{n}}\right]$ is the eigenvector obtained for criteria for expert 1 , multiply this eigenvector by priority element of the expert which is equal to $\mathrm{e}_{1}$. So the new eigenvector for expert ${ }_{1}$ will be $\left[\mathrm{e}_{1} * \mathrm{c}_{11}, \mathrm{e}_{1} * \mathrm{c}_{12} \ldots . \mathrm{e}_{1} * \mathrm{c}_{1 \mathrm{n}}\right]$.

Step 6

The next step is to synthesize the criteria eigenvectors of the individual to obtain combined scores of criterion for the group. For this step we suggest that the aggregation of individual priorities method (geometric mean method or arithmetic mean method) should be used for obtaining the group scores for the ranking of criteria. Let the final eigenvector for the criteria so obtained be donated by $\left[\mathrm{C}_{1}, \mathrm{C}_{2}, \mathrm{C}_{3} \ldots \mathrm{C}_{\mathrm{n}}\right]$.

\section{Step 7}

The next step is to grade the various alternatives on all the criteria using simple ranking method. After the ranking has been obtained we would make pair-wise comparison of the all the alternatives for all the criteria and whenever alternative A scores over the alternative B we would add the eigenvector score as obtained above to the score of alternative A. The matrix so obtained will have to be scaled into an AHP matrix. Therefore we would scale all the elements of the matrix using the formula $\mathrm{e}^{\ln (\alpha)\left(\mathrm{w}_{\mathrm{ij}}-\mathrm{w}_{\mathrm{ji}}\right) /\left(\mathrm{w}_{\mathrm{ij}}+\mathrm{w}_{\mathrm{ji}}\right)}$ where $\alpha=9$ and $\mathrm{w}_{\mathrm{ij}}$ and $\mathrm{w}_{\mathrm{ji}}$ are the elements for the cell $\mathrm{i}-\mathrm{j}$ and cell $\mathrm{j}-\mathrm{i}$ of the matrix obtained as above. The matrix so obtained after scaling should be solved using AHP to obtain the eigenvector or priority vector of the alternatives.

All the steps explained above are difficult to carry manually in order to obtain the relative grading of the projects and the processes in real life situations. Therefore the system developed by us for carrying out group-AHP has also been incorporated to provide the interface for carrying out the grading on the basis of above suggested technique. The system developed has well-developed graphical user interface (GUI) for the ease of the users, carries out all the calculations in backend and provides the results in form of graphs and reports.

\section{Example}

The technique suggested was tested at IBM, India. IBM has a Process Change Request (PCR) scheme. IBM is CMM Level 5 organization. It is one of the essential requirements for Capability maturity Model (CMM) level 5. This is because Level 5 is level of continuous improvement. So they have reward scheme for inviting Process Change requests from the employees. Then the panel of judges ranks these requests and rewards are given to top two process change requests. So the technique suggested and the system developed was used to rank the Process Change requests and select the best PCR.

The first step was to identify the team, which would be evaluating these PCRs. So a team of four experts was selected. The next step was to identify the criteria, which are considered for the evaluation of a PCR. After through discussion and on the basis of research paper published by one of the experts, the group came out with following four criteria shown in Table 1. 


\begin{tabular}{|c|l|}
\hline Symbol & \multicolumn{1}{c|}{ Criterion } \\
\hline A & PCR contributes to shortening cycle time / reducing effort. \\
\hline B & Contributes to improving quality of process deliverables. \\
\hline C & $\begin{array}{l}\text { Suggests innovative practices for meeting process objectives or methods of tailoring process } \\
\text { for different types of projects. }\end{array}$ \\
\hline D & Provides inputs on streamlining processes for making them consistent and structured. \\
\hline
\end{tabular}

Table 1. Criteria for evaluating PCRs

Of all the Process Change Requests so obtained the group selected the six PCR's shown in Table 2 for evaluation.

\begin{tabular}{|c|l|}
\hline Number & \multicolumn{1}{|c|}{ PCR Description } \\
\hline 1 & Provide scenario based configuration management guidelines for different category of projects. \\
\hline 2 & $\begin{array}{l}\text { SRS process must also include Use-cases way of capturing and managing the Functional } \\
\text { requirements of the software system. }\end{array}$ \\
\hline 3 & Refine the guideline for selection of review types to achieve optimal balance. \\
\hline 4 & $\begin{array}{l}\text { Guidelines and criteria for preparing a plan for development of the project plan should be } \\
\text { developed. }\end{array}$ \\
\hline 5 & $\begin{array}{l}\text { Guidelines for selection of appropriate levels of testing with associated benefits should be } \\
\text { addressed in the Testing Process. }\end{array}$ \\
\hline 6 & $\begin{array}{l}\text { To review Project Plan template, which would improve Delivery controls and a "final inspection" } \\
\text { that ensures that all required inspections/tests have been completed }\end{array}$ \\
\hline
\end{tabular}

Table 2. Alternatives

The different experts were asked to prioritize the various criteria using AHP and following data were obtained $^{4}$

Expert 1

\begin{tabular}{|c|c|c|c|c|}
\hline & A & B & C & D \\
\hline A & & V & E & S \\
\hline B & & & E & S \\
\hline C & & & & V \\
\hline D & & & & \\
\hline
\end{tabular}

Expert 3

\begin{tabular}{|c|c|c|c|c|}
\hline & $\mathbf{A}$ & $\mathbf{B}$ & $\mathbf{C}$ & $\mathbf{D}$ \\
\hline $\mathbf{A}$ & & $\mathrm{E}$ & $\mathrm{VX}$ & $\mathrm{X}$ \\
\hline B & & & $\mathrm{VX}$ & $\mathrm{X}$ \\
\hline $\mathbf{C}$ & & & & $\mathrm{S}$ \\
\hline D & & & & \\
\hline
\end{tabular}

Figure 1. Comparison of priorities by four experts
Expert 2

\begin{tabular}{|c|c|c|c|c|}
\hline & A & B & C & D \\
\hline A & & E & SV & X \\
\hline B & & & SV & X \\
\hline C & & & & M \\
\hline D & & & & \\
\hline
\end{tabular}

Expert 4
\begin{tabular}{|c|c|c|c|c|}
\hline & A & B & C & D \\
\hline A & & M & $(\mathrm{S})$ & $(\mathrm{S})$ \\
\hline B & & & $(\mathrm{MS})$ & $(\mathrm{MS})$ \\
\hline C & & & & $\mathrm{E}$ \\
\hline D & & & & \\
\hline
\end{tabular}

The different experts were asked to prioritize the various experts using AHP and data shown in Figure 2 were obtained.

\footnotetext{
${ }^{4}$ The verbal scale for AHP was used in this exercise. $\mathrm{E}=$ Equally, $\mathrm{EM}=$ Equally to Moderately, $\mathrm{M}=$ Moderately, MS $=$ Moderately to Strongly, S = Strongly, SV = Strongly to Very Strongly, V = Very strongly, VX = Very Strongly to Extremely, X = Extremely
} 
Expert 1

\begin{tabular}{|c|c|c|c|c|}
\hline & EX1 & EX2 & EX3 & EX4 \\
\hline EX1 & & E & M & S \\
\hline EX2 & & & M & S \\
\hline EX3 & & & & M \\
\hline EX4 & & & & \\
\hline
\end{tabular}

Expert 3

\begin{tabular}{|c|c|c|c|c|}
\hline & EX1 & EX2 & EX3 & EX4 \\
\hline EX1 & & E & S & S \\
\hline EX2 & & & S & S \\
\hline EX3 & & & & E \\
\hline EX4 & & & & \\
\hline
\end{tabular}

Figure 2. Comparison of the importance of experts
Expert 2

\begin{tabular}{|c|c|c|c|c|}
\hline & EX1 & EX2 & EX3 & EX4 \\
\hline EX1 & & E & S & S \\
\hline EX2 & & & S & S \\
\hline EX3 & & & & E \\
\hline EX4 & & & & \\
\hline
\end{tabular}

Expert 4

\begin{tabular}{|c|c|c|c|c|}
\hline & EX1 & EX2 & EX3 & EX4 \\
\hline EX1 & & E & M & S \\
\hline EX2 & & & M & S \\
\hline EX3 & & & & E \\
\hline EX4 & & & & \\
\hline
\end{tabular}

After obtaining data for all the above matrices the most important member was asked to rank the alternatives for different criteria. Data shown in Table 3 were obtained

\begin{tabular}{|l|l|l|l|l|l|l|}
\hline $\begin{array}{c}\text { Alternatives } \\
\text { Criteria }\end{array}$ & $\mathbf{1}$ & $\mathbf{2}$ & $\mathbf{3}$ & $\mathbf{4}$ & $\mathbf{5}$ & $\mathbf{6}$ \\
\hline A & 2 & 4 & 5 & 1 & 3 & 6 \\
\hline B & 5 & 1 & 2 & 6 & 3 & 4 \\
\hline C & 1 & 4 & 3 & 5 & 2 & 6 \\
\hline D & 3 & 6 & 2 & 4 & 1 & 5 \\
\hline
\end{tabular}

Table 3 Rankings

Based on the data on rankings shown in Table 4 were obtained as output by the system

\begin{tabular}{|c|c|c|l|}
\hline Alternative & Score & Rank & \multicolumn{1}{c|}{ PCR Description } \\
\hline 1 & 0.2472 & 2 & $\begin{array}{l}\text { Provide scenario based configuration management guidelines } \\
\text { for different category of projects. }\end{array}$ \\
\hline 2 & 0.1710 & 3 & $\begin{array}{l}\text { SRS process must also include Use cases as a way of capturing } \\
\text { and managing the Functional requirements of the software } \\
\text { system. }\end{array}$ \\
\hline 3 & 0.1559 & 4 & $\begin{array}{l}\text { Refine the guideline for selection of review types to achieve } \\
\text { optimal balance. }\end{array}$ \\
\hline 4 & 0.1302 & 5 & $\begin{array}{l}\text { Guidelines and criteria for preparing a plan for development of } \\
\text { the project plan should be developed. }\end{array}$ \\
\hline 5 & 0.2506 & 1 & $\begin{array}{l}\text { Guidelines for selection of appropriate levels of testing with } \\
\text { associated benefits should be addressed in the Testing Process. }\end{array}$ \\
\hline 6 & 0.0448 & 6 & $\begin{array}{l}\text { To review Project Plan template, which would improve } \\
\text { Delivery controls and a "final inspection" that ensures that all } \\
\text { required inspections/tests have been completed }\end{array}$ \\
\hline
\end{tabular}

Table 4 Rankings obtained from the system 


\section{Discussion}

In the second phase of this approach where the ranking of the alternatives is on the various criteria is to be done, So we suggest for this phase the person chosen should be the one who has detailed idea about the performance of the various projects or processes in terms of the comparison involved. Therefore say if we are comparing the various e-commerce projects in an organization, the practice (e-commerce) head of the organization should be the one who ranks the various projects because $\mathrm{s} / \mathrm{he}$ is the one who is expected to have detailed idea about the performance of the various projects. That was why the group at IBM agreed to have the most experienced individual in their Software Quality department to compare the alternatives.

One of the advantages of the technique suggested is that it greatly reduces the number of pair wise comparisons involved as compared to traditional AHP problem. For instance, lets say if ' $a$ ' number of alternatives to be evaluated on ' $c$ ' number of criteria by ' $\mathrm{e}$ ' number of experts, we require $\left(\mathrm{c}^{*}(\mathrm{c}-1) / 2+\right.$ $\left.\left.\mathrm{c}^{*} \mathrm{a}^{*}(\mathrm{a}-1) / 2\right)\right)^{*}$ e comparisons. On the other hand by using the approach the number of pair-wise comparison get reduce to $\left(\mathrm{c}^{*}(\mathrm{c}-1) / 2\right) * \mathrm{e}$. We have observed conducting decision making using group AHP that most of the participants to do loose interest because of lot of pair wise comparisons that they have to do. So the approach suggested greatly reduces the comparisons involved, at the same time incorporating the AHP technique into decision-making. One of the difficulties that the IBM faced was to make the people do the AHP based pair-wise comparisons. They found making the comparisons to become cumbersome. We suggest that these kinds of decision-making techniques such as AHP should be regularly incorporated in the training modules of the employees of the organization so that they can be at home while working on these techniques. Not only they should be educated about the ways that they should proceed but also the importance of their contribution to the quality of decision -making.

\section{Conclusion}

In this paper we have suggested an AHP based technique which the organizations will find useful to grade or rate projects and processes. It is an aggregation technique which blends both AHP as well as direct comparison of the alternatives i.e. the projects and processes on various criteria. It then converts this comparison again into an AHP problem to obtain the eigenvector of the alternatives. By suggesting this technique we have attempted to improve on the method proposed by Frei and Harker (1999) by suggesting that how the importance of criteria can also be incorporated in the decision-making. In the approach suggested by Frei and Harker (1999) they attach equal importance to various criteria to evaluate the alternatives under considerations. But in real life it happens that a particular set of criteria score above others in determining the ranking or grading of alternatives. Another draw back in the method suggested by Frei and Harker (1999) was that allowed only one particular expert to participate in decision-making or took single concrete scores from the group. We have suggested the technique to allow the group of experts to participate in the decision-making and hence enhance the quality of decision making involved. The technique suggested by us allows the various experts to give their won judgement and suggests ways to aggregate the scores suggested by them. Another issue which the new technique has tried to address is to incorporate the due weightages to the experience, qualifications and skills of the various experts involved so that the importance of knowledge and abilities of the experts gets due recognition.

One of the other advantages of this technique is that it reduces the comparison matrices as used in the traditional Group AHP technique thus saving time and ambiguity.

One of the drawbacks of this technique is that it does not take account of the subjectivity involved in the comparison of the alternatives. The technique just takes into account that process $\mathrm{A}$ being better than process $\mathrm{B}$, but does not takes into account as to what degree the process $\mathrm{A}$ is better. That is a variant that we are currently working on by incorporating the concept of agreement index to refine the interpretation of the final results of the ranking process. The other issue that we are working on includes involving the entire group in the comparison of alternatives with respect to criteria. Future work will focus on ways to involve the whole group on the second stage also. 


\section{References}

Aczel, J. and Saaty, T. (1983) Procedures for synthesizing ratio judgments, Journal of Mathematical Psychology, 27, 93-102.

Forman, E. H. and Peniwati, K. (1998) Aggregating individual judgments and priorities with the Analytic Hierarchy Process, European Journal of Operational Research, 108(1), 165-169

Frei, F. X. and Harker, P. T. (1999), Measuring aggregate process performance using AHP, European Journal of Operational Research, 116(2), 436-442.

Monga, I. S. (2000) Aggregating individual scores in-group analytic hierarchy process: A comparison of competing approaches, M. Tech. Thesis, Department of Management Studies, Indian Institute of Technology, Delhi.

Ramanathan, R. and Ganesh, L.S (1994) Group preference aggregation methods employed in AHP: An evaluation and an intrinsic process for deriving members weightages, European Journal of Operational Research, 79 (2), 249-265. 